\title{
DIFERENCIAS DEL CONCEPTO SOBERANÍA ENTRE CONSTITUCIÓN DE CÁDIZ DE 1812 Y SENTIMIENTOS DE LA NACIÓN: GERMEN PARA CONSTITUCIÓN DE APATZINGÁN DE 1814
}

\author{
Sovereignty concept differences between cadiz constitution of 1812 and the national \\ feelings: germ for apatzingan constitution of 1814
}

Francisco Felipe de Jesús Pérez Alejandre ${ }^{1}$

Sumario:

I. Introducción. II. Antecedentes de la Soberanía en el Derecho Castellano y en lo que fue Nueva España. III. La Soberanía en la Constitución de Cádiz de 1812. IV. La Soberanía en Sentimientos de la Nación y la Constitución de Apatzingán de 1814. V. Conclusiones. VI Fuentes Consultadas.

Resumen. En el año de 1812 es expedida la Constitución de Cádiz, con una visión de soberanía que solo reflejaba las aspiraciones, identidad e intereses de los españoles que eran de la península ibérica, los diputados del constituyente de Cádiz en su mayoría peninsulares habían hecho a un lado las demandas y planteamientos de los diputados de las provincias de ultramar, principalmente americanos; lo que en muchos reafirmo las ideas libertarias y movimientos de independencia de la mayoría de los territorios americanos, como sucedió en Nueva España al verse reflejado esto en "Sentimientos de la Nación" y en la Constitución de Apatzingán de 1812, que reclamaban una soberanía popular para el bien del pueblo del naciente México.

Palabras Clave: Soberanía, Constitución, Apatzingán, Cádiz.

Abstract. In the year 1812 it issued the Constitution of Cadiz, with a vision of sovereignty that only reflected the aspirations, identity and interests of the spanish who were of the Iberian Peninsula, the deputies of the Cádiz constituent of most Spaniards had made a aside the demands and proposals of the represents of the overseas provinces, mostly americans, which in many reaffirm the freedom ideas and indepedence movements of most American territories, as in New Spain to be reflected in "Feelings of this Nation" and the Constitution of Apatzingan of 1812, claiming popular sovereignty for the good of the people of Mexico rising.

Keywords: Sovereignty, Constitution, Apatzingan, Cadiz.

\footnotetext{
${ }^{1}$ Licenciado en Derecho por la Universidad Nacional Autónoma de México, Maestro en Derecho por la Facultad de Derecho de la UNAM, Ex becario CONACyT, Profesor de Tiempo Completo en la Licenciatura de Derecho y en la Maestría de Derecho, en la Facultad de Ciencias Administrativas y Sociales, Campus Valle Dorado, Vice Rectoría Ensenada de la Universidad Autónoma de Baja California.
} 


\section{INTRODUCCIÓN}

Antes de 1808 España era una monarquía absoluta en la cual la soberanía emanaba de un monarca absolutista, una soberanía que desde tiempos medievales provenía de las Cortes, que representaban a los sectores de la sociedad española nobleza, clero y ayuntamientos; sin embargo, con la Revolución Francesa y las guerras napoleónicas, se manifestó el cambio en el pensamiento de la mayoría de los españoles y de los habitantes de las que denominaron las provincias de ultramar y posteriormente fueron los países hispanoamericanos, por ello exigieron un cambio en la forma del Estado, que culminaría en dos leyes fundamentales, la Constitución de Cádiz de 1812 y la Constitución de Apatzingán de 1814, las cuales fueron la expresión de las ideas de dos grupos, que tenían ideas liberales a veces muy parecidas, pero muy distintas de lo que debía considerarse como soberanía, como se analizará a continuación.

\section{ANTECEDENTES DE LA SOBERANÍA EN EL DERECHO CONSTITUCIONAL CASTELLANO Y EN LO QUE FUE NUEVA ESPAÑA}

Cuando Alfonso X el Sabio llamo a las Cortes en el siglo XII, para crear la ley fundamental del reino, las Siete Partidas, la soberanía le había sido otorgada al monarca por las Cortes, en las cuales estaba representada la nobleza, la iglesia y los ayuntamientos de las ciudades o municipios que conformaban el reino, ${ }^{2}$ era una soberanía un tanto pactada, "el municipio nombraba a sus representantes, llamados procuradores, para que reunidos con los de otros municipios, cuando las circunstancias lo exigieran, formaran las Cortes, cuerpo deliberativo, legislador y fiscalizador de la Corona".

Algunos de los conquistadores eran gente educada y conocedores de las leyes de Castilla, ${ }^{4}$ por lo que sabían la importancia de la figura jurídica del ayuntamiento, que en momentos determinados podían ser fundados para llevar la autoridad del monarca español en tierras en donde no existía gobierno aún.

Por ello Hernán Cortes y sus expedicionarios para no depender del Gobernador de Cuba, ni ser considerados rebeldes en contra del rey, en 1519, fundan el Ayuntamiento de la Villa Rica de Veracruz, ${ }^{5}$ con ello se deposita la soberanía del primer Ayuntamiento de lo que sería Nueva España a Carlos V, esta fue la primera manifestación de Soberanía de los súbditos españoles en América.

El rey Carlos I de España y V de Alemania, dado que es un monarca proveniente de la casa de los Habsburgo austriacos, su concepción de la soberanía era distinta a la española, ya que para él la soberanía era proveniente de Dios y esta era depositada en los monarcas; por lo tanto la capacidad jurídico soberana del municipio cambia en 1521 como señala Francisco R. Calderón:

\footnotetext{
${ }^{2}$ Brading, David, Orbe Indiano, trad. Juan José Utrilla, México, FCE, 1991, p. 583.

3 Calderón, Francisco R., Historia económica de la Nueva España en tiempo de los Austrias, México, FCE, 1988, pág. 128.

4 Grumberg, Bernard, "El universo de los conquistadores: Resultado De una Investigación prosopográfica”, Signos Históricos, México, UAM - Iztapalapa, núm. 12, julio - diciembre 2004, p. 99.

5 López Monroy, José de Jesús, “Funcionalidad autárquica de los ayuntamientos”, Memoria del Simposio Internacional 1808: A doscientos años y el origen de los Derechos Humanos, Anuario mexicano de Historia del Derecho, México, UNAM, Instituto de Investigaciones Jurídicas, núm. XXI, 2009, pp. 2 - 4.
} 
Este tipo de gobierno representativo nunca tuvo lugar en la América española porque al momento de la Conquista el ejército de los municipios de Castilla fue derrotado por las fuerzas del Rey - Emperador en la batalla de Villalar y con ello las comunidades perdieron su poder e independencia y los reyes fueron sumamente suspicaces de los privilegios o pretensiones de las corporaciones municipales. ${ }^{6}$

Aún con lo anteriormente referido y un poder minado, el ayuntamiento fue en muchos aspectos órgano básico y representativo de gobierno, entre este y el rey no había intermediarios.

Es de señalar también que la corriente jurídica de la época consideraba como un verdadero reino a la Nueva España es decir que tenía una soberanía propia, por lo que no era una colonia, sino uno de los tantos reinos que conformaban la corona de Castilla, por lo que el único vínculo de derecho entre España y las Indias era su monarca. "Vitoria y Las Casas consideraban a los de Indias como estados perfectos que se gobernaban así mismos en cuanto tenían sus propias leyes, autoridades y magistrados." ' Además se debe señalar que las distancias entre las Indias y la Metrópoli eran enormes por lo que era lógico que debiera dotarse de cierta autonomía a los reinos indianos.

Sin embargo Carlos V y su hijo tuvieron una idea muy distinta de cómo debieron administrarse las indias como lo señala Francisco R. Calderon:

... la política seguida fue la de llegar a centralizar el ejercicio del poder en los órganos de gobierno asentados en España que asesoraban al rey en las cuestiones. Así muy pronto se desarrolló una teoría oficial que consideraba a las Indias unidas a Castilla por accesión sin constituir un reino separado. Carlos V parece haberlo entendido así al estatuir que las Indias Occidentales estuvieran siempre unidas a la Corona de Castilla y no se pudieran enajenar; Felipe II fue todavía más explícito cuando se refirió en 1556 a "los reinos de Castilla y León y lo anexo y dependiente a ellos, en que se incluyen esos estados de las Indias ..."

Esta manera de ver a los reinos de Indias permanecería sin muchos cuestionamientos por casi trescientos años.

Las Siete Partidas y toda una serie de mecanismos constitucionales escolásticos medievales, y las ideas jusnaturalistas sobre la soberanía de las Indias no volvieron a cobrar importancia hasta 1808 , año en que estalló una crisis constitucional, debida a la invasión napoleónica, la abdicación de Carlos IV y de Fernando VII, y la imposición en el trono de José Bonaparte hermano de Napoleón, dado que el nuevo rey es un usurpador y no hay un gobernante legítimo, la soberanía, conforme a las siete partidas y la doctrina "del pactismo o doctrina populista de la segunda escolástica española."9 Regresa a los detentadores originales que son representados en las Cortes y los ayuntamientos, lo que provoca el fenómeno del juntismo en toda España y en los reinos ultramarinos; aunque en lo referente a los reinos españoles en América esto no fue muy bien visto por los españoles originarios de la península, pues esto le dada a los criollos la posibilidad de participar más activamente en el gobierno y de despojar a los peninsulares de sus privilegios; esto se vio reflejado en el intento que realizó el ayuntamiento de la Ciudad de México, órgano de gobierno con más representatividad

\footnotetext{
${ }^{6}$ Calderón, Francisco R., Op. cit., p. 128.

7 Ibidem, p. 118.

8 Ibidem, pp. 118 - 119.

9 Pampillo Baliño, Juan Pablo, “Pensamiento Independentista de Melchor de Talamentes”, Anuario mexicano de Historia del Derecho Op. Cit., p. 8 o.
} 
criolla, respaldado por el virrey Iturrigaray para establecer una Junta y llamar a Cortes, con fundamento en las ideas expuestas por Francisco Primo Verdad y Francisco de Azcarate, que se basaban en la idea de que la soberanía al no poder ser ejercida por el rey, esta regresaba a la Nación; este movimiento fue socavado por un golpe de Estado encabezado por Gabriel de Yermo, rico peninsular y hacendado representante de los comerciantes peninsulares que vivían del comercio monopolista con España, respaldado por la Real Audiencia, el arzobispo Francisco Xavier de Lizana y el partido europeo; ${ }^{10}$ que consideraban que Nueva España no tenía una soberanía propia, pues era un reino accesorio de Castilla; lo que puso punto final al intento pacífico de autonomía o Independencia de Nueva España. ${ }^{11}$ Todo esto reflejaba un desgaste en el sistema constitucional no solo en perjuicio de España sino también de los reinos ultramarinos, lo que es bien retratado por Miguel Ramos Arizpe:

$\mathrm{N}^{\circ}$ 18. Es un hecho tan notorio como digno de llorarse, que el gobierno de la monarquía española, por error, ignorancia y muchas veces por interés de familia u otras miras particulares, en el largo espacio de tres siglos, ha fijado todos sus conatos en sólo el engrandecimiento, lujo y extraordinario esplendor de sus gobernadores, lo es también que, siendo imposible conciliar siempre estas miras con los derechos de la nación y fomento de su prosperidad, resultó un terrible choque de intereses entre ésta y sus gobernadores, y venciendo el poderío, vinieron a tierra los más sagrados derechos del hombre, adoptándose desde luego sistemas adecuados para asegurar en el trono y sus cercanías al despotismo, a la arbitrariedad, a la estupidez y mil veces al vicio mismo. ${ }^{12}$

El nuevo gobierno virreinal encabezado por peninsulares que no querían perder sus canonjías, en 1809 dependía ya no del rey sino de una regencia, la cual para poder adquirir cierta legitimidad y tratar de reconciliarse con los reinos americanos convoca a Cortes generales, las cuales serían detentadoras de la soberanía en el tiempo en que Fernando VII "El Deseado" estuviera ausente; a las Cortes asistirán diputados de todos los reinos españoles, ${ }^{13}$ predominando una mayoría de 150 delegados españoles, contra 53 americanos; lo que en cierta manera reflejaba el menosprecio y miedo que sentían los europeos por sus contrapartes americanas de las que creían que deseaban independizarse.

En Nueva España los criollos al no tener opción pacífica para acceder al gobierno y ejercer la soberanía comienzan a conspirar, el primer intento es en 1809 encabezado en Valladolid, encabezado por el capitán José María García Obeso y don José Mariano de Michelena, pero son descubiertos, ${ }^{14}$ el siguiente intento, se da en Querétaro, en el que criollos importantes participan, como Miguel Hidalgo y Costilla párroco del pueblo de Dolores y el capitán Ignacio Allende, también son descubiertos, por ello deciden pasar a la acción y lo que en un principio fue un movimiento criollo se convirtió en uno en que el que se convocó a bases populares, al convocarse también a las castas mestizas, rancheros, negros, esclavos e indios.

Dado el desarrollo de los acontecimientos muchos criollos deciden discrepar de las ideas de Hidalgo, pero muchos otros se le unen, entre ellos José María Morelos y Pavón cura de

\footnotetext{
${ }^{10}$ Villoro, Luis, "La Revolución de Independencia”, Historia General de México / obra preparada por el Centro de Estudios Históricos Versión 2000, México, El Colegio de México, 2000, pp. 502-503.

${ }^{11}$ Abreu y Abreu, Juan Carlos, "El dilema del ocaso novohispano", Anuario mexicano de Historia del Derecho Op. Cit., pp. 203-205.

${ }^{12}$ Ramos Arispe, Miguel, “Raíces del federalismo en México. 1812”, Matute, Álvaro (comp.), Antología México en el siglo XIX, Fuentes de Interpretación Históricas, $t$. XII, Lecturas Universitarias, $3^{\text {a }}$ ed., México, UNAM, 1981 , p. 209.

${ }^{13}$ Brading, David, Op. Cit., p. 582.

${ }^{14}$ Villoro, Luis, Op. Cit., p.503. 
Carácuaro, que había sido discípulo de Hidalgo en el Colegio de San Nicolás; Hidalgo comisiona a Morelos el llevar el movimiento Insurgente al sur del Virreinato; al ser derrotado y ejecutado Hidalgo, Morelos se convertirá en el continuador e ideólogo máximo del movimiento de Independencia, con el paso del tiempo lo que era un movimiento para reivindicación de derechos políticos y de autonomía para los criollos, se convirtió en una revolución de independencia popular que también busco reivindicación social de las castas y los indios, en la cual la soberanía ya no sería considerada de la manera escolástica en que era entendida.

\section{LA SOBERANÍA EN LA CONSTITUCIÓN DE CÁDIZ DE 1812}

Las Cortes se reúnen en la isla de León, cerca de Cádiz el 24 de septiembre de 1810, con la ausencia del rey.15 Aunque privara un ambiente liberal afrancesado muy parecido al de la Asamblea Nacional francesa de 1789, pero también existía ese aspecto nostálgico por el constitucionalismo escolástico, "Desde luego declararon que la soberanía residía en la cámara única representante del pueblo."16 Para febrero de 1811 las Cortes se mudaron a Cádiz para seguir con sus deliberaciones, que llevaron a la redacción y promulgación de la Constitución Política de la Monarquía Española, el 19 de marzo de 1812; la cual estableció sobre la Nación y la Soberanía lo siguiente:

Art. 1. La Nación española es la reunión de todos los españoles de ambos hemisferios.

Art. 2. La Nación española es libre e independiente, y no es ni puede ser patrimonio de ninguna familia ni persona.

Art. 3. La soberanía reside esencialmente en la Nación y por lo mismo pertenece a ésta, exclusivamente, el derecho de establecer sus leyes fundamentales. ${ }^{17}$

Con esto se observa que en la Constitución de Cádiz la soberanía reside en la Nación, que se basa en caracteres identitarios, ${ }^{18}$ "... las Cortes españolas se presentaban en sus inicios como un retorno a las viejas instituciones democráticas sepultadas por el despotismo"19, es decir en cuestiones que identifican a España como lo son la religión, el reino y el rey; éste último depositario de la soberanía, que le es otorgada por las Cortes como representantes de la Nación, autoridad que le otorgan los ayuntamientos, que eran los únicos órganos democráticos en el esquema de gobierno español y representantes del pueblo, pero no es el pueblo en su concepción ilustrada, sino el pueblo visto desde el punto de vista de Vitoria y de Suárez, ${ }^{20}$ el cual jura lealtad a su soberano exigiéndole que no haya intermediarios entre pueblo y monarca, lo que no era posible pues Fernando VII era prisionero de los franceses,

\footnotetext{
${ }^{15}$ Ibidem, pp. 511-512.

16 Idem.

17 Tena Ramírez, Felipe, Leyes Fundamentales de México 1808 - 2002, 23ª ed., México, Porrúa, 2002, p. 60.

${ }^{18}$ Abreu y Abreu, Juan Carlos, "Las ideas constitucionales en México en el marco de las cortes gaditanas", Mesa 1 La Constitución de Cádiz: la importancia de un pensamiento liberal frente a la monarquía, Seminario Encuentro sobre la Constitución de Cádiz y los Derechos Humanos, México, Instituto de Investigaciones Dr. José María Luis Mora -Comisión Nacional de los Derechos Humanos, 31 de agosto- 2 de septiembre de 2009.

19 Villoro, Luis, El Proceso Ideológico de la Revolución de Independencia, Cien textos fundamentales para el mejor conocimiento de México, $2^{\text {a }}$ ed., México, CONACULTA, 1999, p. 116.

${ }^{20}$ Pampillo Baliño, Juan Pablo, Op. Cit., p. 80.
} 
por eso es el pueblo en este contexto el que tiene la soberanía en ausencia de su monarca, que al regresar éste, le sería depositada por el pueblo representado en las Cortes.

Estas ideas plasmadas en un ambiente de triunfo en la Constitución de Cádiz, pero solo se cuidaba los derechos de los españoles blancos y que solo se les reconocía a ellos como parte del pueblo detentador de la soberanía; lo que se quedaba corto en cuanto a las ideas e intereses que expresaron los diputados novohispanos, que exigían más derechos para sus representados y las castas en América, como lo señala Luis Villoro:

[...] la actitud de los diputados americanos era de hecho más radical que la de los europeos. Con denuedo defendieron los derechos de ciudadanía de los indios, los negros y las castas, exigieron la abolición de la esclavitud y reclamaron la supresión de alcabalas y la libertad de producción y comercio para todos los reinos hispánicos. [...] En un pliego de peticiones resumieron los agravios más importantes de las colonias. Pedían, en síntesis: igual representación a cortes para España y América; libertad de explotación agrícola e industrial; libertad de comercio; supresión de los estancos; libertad de explotación minera; igualdad en la distribución de empleos entre peninsulares y americanos, y restitución de los jesuitas. ${ }^{21}$

La Constitución de Cádiz de 1812 es por derecho la primera ley fundamental que rigió a México, todavía Nueva España, promulgada el 30 de septiembre de 1812; esta Ley Fundamental no tuvo una aplicación completa en nuestro territorio por los conflictos de la revolución de Independencia; otorgó garantías nunca antes gozadas por los súbditos de Nueva España entre ellos cierta igualdad entre americanos y europeos, y la atribución de la soberanía por parte de la Nación "en ausencia del monarca, a la voluntad general de los ciudadanos, "Fue la proclamación de la libertad de imprenta, aunada a la abolición del tribunal de la inquisición, lo que fomentó acuciadamente y por modo intenso y diversificado las publicaciones de los partidarios de nuestra emancipación política tendientes a socavar al gobierno virreinal."22 Todo lo anterior fue en contra del antiguo despotismo de las autoridades desde los reyes, pasando por los virreyes hasta los funcionarios virreinales, solo había un detalle, la igualdad y la libertad que otorgaba Cádiz solo era para unos cuantos, los españoles de ambos hemisferios, ya que "las castas y los negros deberían participar de esa paridad que la nueva constitución aún les negaba”. ${ }^{23}$ Ellos no podían ejercer la soberanía pues no tenían representantes ante las Cortes y no eran considerados por entero parte de la Nación.

Aún con la serie de reformas y concesiones que se otorgaban en la Constitución gaditana a los reinos americanos, no se pudo detener los movimientos independentistas que buscaban la soberanía para sus naciones y no una supeditada a la Nación española que durante mucho tiempo desconoció su calidad de reinos o estados, con necesidades propias distintas a las de España. La Constitución de Cádiz tuvo una vigencia efímera, pues fue abolida por Fernando VII y en la Nueva España tuvo oposición por parte de los españoles y los criollos ricos, lo que derivó también en su abolición por parte del virrey Calleja en agosto de 1814; dado este retroceso al autoritarismo, muchos intelectuales criollos decidieron unirse a la causa Insurgente encabezada por Morelos. ${ }^{24}$

La Constitución de Cádiz de 1812 era un gran avance para el pueblo español, con muchas carencias para los americanos; pero sirvió de ejemplo para la elaboración de las leyes funda-

\footnotetext{
${ }^{21}$ Villoro, Luis, "La Revolución de Independencia", Op. Cit. p. 512.

${ }^{22}$ Burgoa Orihuela, Ignacio, Derecho Constitucional Mexicano, $17^{\mathrm{a}}$ ed., México, Porrúa, 2005, página 470.

${ }^{23}$ Villoro, Luis, "La Revolución de Independencia", Op. Cit. p.. 513.

${ }^{24}$ González, Luis, "El periodo formativo", Cosío Villegas, Daniel et al., Historia mínima de México, México, El Colegio de México, 1973, p. 87.
} 
mentales de los futuros países hispanoamericanos, y para las que rigieron a México después de su independencia.

IV. LA SOBERANÍA EN SENTIMIENTOS DE LA NACIÓN Y LA CONSTITUCIÓN DE APATZINGÁN DE 1814

Con el movimiento de Independencia avanzado, se hizo evidente la necesidad de crear una Ley Fundamental que diera identidad y organización al Estado que nacía, en 1813 fue el año en que se logró la madurez ideológica para ello:

El 13 de septiembre, con el discurso de Morelos y la lectura de los Sentimientos de la Nación, se inauguraron las sesiones de la primera Asamblea Representativa Independiente, lo que culminó con la declaración de Independencia absoluta, repudio a la monarquía, adopción del sistema republicano y constitucional para normar la acción renovadora de la libertad y de la justicia social; logros que la insurgencia heredó a los mexicanos en Chilpancingo y Apatzingán: es decir las bases para el primer proyecto de la nación mexicana. ${ }^{25}$

Morelos tenía una preparación ilustrada, había leído a los enciclopedistas y sus escritos tenían la influencia no solo francesa sino también de los pensadores estadounidenses, las cuales establecían que la soberanía dimanaba del pueblo, eso lo podemos ver reflejado en "Sentimientos de la Nación" en el artículo $5^{\circ}$ que dice:

La Soberanía dimana inmediatamente del Pueblo, que sólo quiere depositarla en sus representantes dividiendo los poderes de ella en Legislativo, Ejecutivo y Judiciario, eligiendo las provincias sus vocales y éstos a los demás, que deben ser sujetos sabios y de probidad. ${ }^{26}$

El Congreso Constituyente de Chilpancingo y Apatzingán estaba conformado por representantes de los territorios liberados por la insurgencia, "hombres doctos, patriotas y excelentes publicistas"27 tenían también ideas de corte liberal moderno, inspirados en las constituciones francesas, la estadounidense, en los "Los Sentimientos de la Nación" de Morelos para la nueva constitución, la cual sería la base para crear una Nación y dotar de identidad jurídica al movimiento insurgente que era de tipo popular, "no se trata ya de una junta de ayuntamientos y otras corporaciones destinada a guardar la soberanía y gobernar el reino según sus leyes fundamentales; sino de un cónclave de ciudadanos, representantes del pueblo, facultados para constituir un nuevo Estado. ${ }^{28}$

Se trataba ahora de plasmar en el Decreto Constitucional para la Libertad de la América Mexicana, una visión distinta de soberanía, que sería la soberanía popular, lo que se logró expresar en Apatzingán el 22 de octubre de 1814, de la siguiente manera:

Art. $2^{\circ}$ La facultad de dictar leyes y establecer la forma de gobierno, que más convenga a los intereses de la sociedad, constituye la soberanía.

Art. $3^{\circ}$ Esta es por su naturaleza imprescriptible, inajenable e indivisible.

Art. $4^{\circ}$ Como el gobierno no se instituye por honra o intereses particulares de ninguna familia, de ningún hombre ni clase de hombres, sino para la protección y seguridad general de todos los ciudadanos, unidos voluntariamente en sociedad, ésta tiene derecho incontesta-

\footnotetext{
${ }^{25}$ García Díaz, Tarsicio, “Morelos culmina el proyecto de nación”, García Díaz, Tarsicio (coord.), Independencia Nacional, Fuentes y Documentos, México, UNAM, Instituto de Investigaciones Bibliográficas, 2007, p. 115 .

${ }^{26}$ Morelos y Pavón, Jose María, “Sentimientos de la Nación”, Matute, Álvaro (comp.), Op. cit., p. 224.

27 De la Torre Villar, Ernesto, La independencia de México, México, FCE - Editorial MAPFRE, 1992. p. 101.

${ }^{28}$ Villoro, Luis, El Proceso Ideológico de la Revolución de Independencia, Op. cit. p. 119.
} 
ble a establecer el gobierno que más le convenga, alterarlo, modificarlo y abolirlo totalmente cuando su felicidad lo requiera.

Art. $5^{\circ}$ Por consiguiente, la soberanía reside originariamente en el pueblo, y su ejercicio en la representación nacional compuesta de diputados elegidos por los ciudadanos bajo la forma que prescriba la constitución. ${ }^{29}$

El Decreto Constitucional para la América Mexicana, buscó concretar la necesidad de igualdad y de libertad; con un capítulo que consagró los derechos del hombre, que debían ser respetados y protegidos por el poder público, por sobre todas las cosas; con ello reconoció los derechos de todos los habitantes, con lo que quedaban abolidas las castas, la esclavitud y el impuesto sobre los indios; teniendo un concepto ilustrado sobre lo que era el pueblo y la soberanía; además de retomar los principios republicanos y democráticos, en donde era la soberanía es depositada y representada exclusivamente por el Congreso, un Congreso fuerte que nombraba a los otros poderes, a los que delegaba de modo temporal facultades ${ }^{30}$; un poder ejecutivo muy acotado, para evitar que el fantasma del "despotismo" lo que destruyo a la naciente República, que no dio facultades especiales a Morelos para hacer frente a la guerra contra los realistas.

Es de reconocer que la Constitución de Apatzingán estableció la división bien definida en tres poderes en ejecutivo, legislativo y judicial; también rompe totalmente con la idea de estar sujeto a la monarquía española, con esto fue más allá de la Constitución de Cádiz de 1812.

\section{CONCLUSIONES}

La idea original de Soberanía en el Derecho castellano, data de la edad media cuando Alfonso X "el Sabio" ordena la reunión de la Cortes, en las cuales están representados la nobleza, el clero y los ayuntamientos, estos últimos sus representantes eran elegidos por el pueblo, es decir los españoles libres que residen en las ciudades y pueblos; siendo un órgano democrático. Las Cortes y ayuntamientos son las detentadoras originarias de la soberanía la cual la otorgan al monarca al jurarle fidelidad, entre los ayuntamientos y el monarca no hay intermediarios.

El ayuntamiento que es el órgano básico de gobierno en el Derecho castellano, es la primera institución jurídica que es traída a lo que sería Nueva España por Hernán Cortes y sus hombres en 1519, para dar sustento jurídico a la conquista, y solo rendir cuentas directamente al rey.

Las ideas de la antigua Constitución, las siete partidas y la jurisprudencia antigua sobre la soberanía restituida a las Cortes y los ayuntamientos; vuelven a cobrar importancia debido a la crisis constitucional que vivió España en 1808, por la invasión napoleónica y la imposición de un usurpador, lo que es realizado en España por los reinos y ayuntamientos al crearse las juntas. Lo que no puede consolidarse en Nueva España pues los peninsulares y criollos ricos; ante el intento realizado por el ayuntamiento de la ciudad de México y el virrey Iturrigaray, de llamar a cortes y darle cierta autonomía al reino; realizan un golpe de Estado, con el argumento de que el virreinato de Nueva España no es un reino como tal sino dependiente de Castilla, por lo que se atendrá a lo dispuesto por la junta Suprema y después regencia que tubo sede en Cádiz.

\footnotetext{
29 Tena Ramírez, Felipe, Op. cit., pp. 32 - 33.

${ }^{30}$ Villoro, Luis, "La Revolución de Independencia", Op. Cit. p. 514. 
Todo ello denotó la crisis constitucional por la que vivía la monarquía española, la cual debía convertirse de una monarquía absolutista a una constitucional.

Lo anterior ya era insuficiente en los reinos ultramarinos de América pues en varios de ellos se exigían cambios más profundos.

La regencia que tendrá su sede en Cádiz llama a Cortes y convoca a diputados de todos los reinos que conforman al Imperio Español para crear una nueva Constitución, basándose en la idea de que la soberanía la tiene el Congreso que se reunirá en Cádiz.

La idea de Soberanía se basa en las ideas escolásticas y de las Siete Partidas que hay sobre ésta, además de que hay influencia francesa ilustrada, siendo una idea de soberanía que reside en la Nación, dándole esto características identitarias de lo que es España, con las cuales no están identificados los reinos ultramarinos, basadas en la idea de rey, reino y religión, lo que se verá plasmado en la Constitución de Cádiz. Una Soberanía que reside en la Nación representada por las Cortes y que la depositará en el rey Fernando VII “el deseado”, legítimo gobernante, cuando regrese de su cautiverio al que está sometido con el invasor francés. Pero que es una nación conformada tan solo por españoles libres y en la cuanto hay una igualdad y libertad plenas.

En Nueva España debido a que los intentos pacíficos de los criollos por ejercer su el gobierno de manera conjunta con los peninsulares, se empiezan a realizar conjuras, lo que lleva al movimiento de Independencia encabezado por Hidalgo y continuado por Morelos, éste último junto con el congreso de Chilpancingo, primero con "Sentimientos de la Nación" y posteriormente con la Constitución de Apatzingán, darán identidad jurídica al movimiento de Independencia y plasmarán la idea de Soberanía Popular, denotando una influencia de los pensadores de la Ilustración francesa y del constitucionalismo estadounidense del siglo XVIII, en donde el pueblo está conformado tanto por criollos, indios negros y mestizos, quedando abolidas la esclavitud, las castas y los impuestos sobre los indios; la idea de Soberanía popular en Apatzingán rompe totalmente con la idea de soberanía que reside en la nación de Cádiz.

La Constitución de Cádiz tendrá una fuerte influencia en Leyes fundamentales posteriores en el naciente Estado Mexicano.

La soberanía que existió en Nueva España, fue una soberanía absolutista, después una soberanía nacional y al final una soberanía popular al consolidarse como Nación Mexicana.

Las enseñanzas liberales de Apatzingán sobre Soberanía Popular y Derechos del Hombre serán retomados hasta la Constitución de 1857. Las enseñanzas e ideas de reivindicación social que se estaban dando en la primera parte del movimiento de Independencia, en muchos casos serán olvidadas y solo serán retomadas hasta la Revolución de 1910 y plasmadas en la Constitución de 1917.

VI. BIBLIOGRAFÍA

BRADING, David, Orbe Indiano, trad. Juan José Utrilla, México, FCE, 1991.

BURGOA ORIHUELA, Ignacio, Derecho Constitucional Mexicano, $17^{\mathrm{a}}$ ed., México, Porrúa, 2005.

CALDERÓN, Francisco R., Historia económica de la Nueva España en tiempo de los Austrias, México, FCE, 1988. 
COSÍO VILlEGAS, Daniel et al., Historia mínima de México, México, El Colegio de México, 1973 .

DE LA TORRE VILLAR, Ernesto, La independencia de México, México, FCE - Editorial MAPFRE, 1992.

GARCÍA DÍAZ, Tarsicio (coord.), Independencia Nacional, Fuentes y Documentos, México, UNAM, Instituto de Investigaciones Bibliográficas, 2007.

GRUMBERG, Bernard, "El universo de los conquistadores: Resultado De una Investigación prosopográfica”, Signos Históricos, México, UAM - Iztapalapa, núm. 12, julio - diciembre 2004 .

MATUTE, Álvaro (comp.), Antología México en el siglo XIX, Fuentes de Interpretación Históricas, $t$. XII, Lecturas Universitarias, $3^{\text {a }}$ ed., México, UNAM, 1981.

TENA RAMÍREZ, Felipe, Leyes Fundamentales de México 1808 - 2002, 23 ed., México, Porrúa, 2002.

VILLORO, Luis, El Proceso Ideológico de la Revolución de Independencia, Cien textos fundamentales para el mejor conocimiento de México, $2^{\mathrm{a}}$ ed., México, CONACULTA, 1999.

Anuario mexicano de Historia del Derecho, México, UNAM, Instituto de Investigaciones Jurídicas, núm. XXI, 2009.

Historia General de México / obra preparada por el Centro de Estudios Históricos Versión 200o, México, El Colegio de México, 2000.

Conferencias

ABREU Y ABREU, Juan Carlos, "Las ideas constitucionales en México en el marco de las cortes gaditanas", Mesa 1 La Constitución de Cádiz: la importancia de un pensamiento liberal frente a la monarquía, Seminario Encuentro sobre la Constitución de Cádiz y los Derechos Humanos, México, Instituto de Investigaciones Dr. José María Luis Mora - Comisión Nacional de los Derechos Humanos, 31 de agosto - 2 de septiembre de 2009. 